\title{
The Study of the Relationship between Accessibility and Mixed Land Use in Tainan, Taiwan
}

\author{
Shu-Wei Huang and Hsiu-I Hsieh
}

\begin{abstract}
Mixed land-use is one of the long-term policies to land management in most Asian countries. In the recent, it not only been advocated by new urbanism, but also the important land planning concept of smart growth and compact city in America and many European countries. Land use and transportation both are the important elements for urban and regional development. In the recent, new urbanism promoted mixed land use to be a land developmental type, in the meantime, the concept and importance of Transit-Oriented Development was emphasized. It was mean that mixed land use and transportation need to cooperate to achieve the goal of good urban development. In this paper, in addition to measure the degree of mixed land use, it also provides the new method and concept of accessibility, adopting the spatial accessibility of road network to examine the relationship between transportation system and mixed land-use, to view whether transportation system and mixed land-use can coordinate each other that it contributes to establish strategies for land use, transportation planning and management; on the other hand, the analysis theory and method can be used to explore the structure and patterns of urban development further for other relevant departments reference when establishing the policies.
\end{abstract}

Index Terms-Mixed land-use, diversity, space syntax

\section{INTRODUCTION}

Mixed land-use is the main characteristic of urbanization in many countries in Asia, it plays a very important role in socio-economic development for Asian cities [1]. In recent years, new urbanism advocates the community space within walking distance should content living, consuming, work, entertainment and other various needs for life that mixed land-use is one of major demands. Through diverse land use with public transport system and complete footpaths network, it can achieve the purpose of enhancing land-use performance [2]. Therefore, mixed land-use is not only the important principle of urban smart growth and land use planning, but also the main policy currently in many cities in America [3], and part of countries in European develop towards mixed land-use gradually under the theory of compact city [4]-[6]. Mixed land-use is a common fact in Taiwan already, lots of countries and cities start to consider how to create the more appropriate types of mix land-use in the case. In Taiwan, the patterns of mixed land-use have a long-term process of development that evolutes from the history of the of habits formed, these long-standing analysis cases of mixed land-use enable achieving greater purpose of

Manuscript received October 10, 2013; revised December 3, 2013.

The authors are with the Department of Environmental and Cultural Resources, National Hsinchu University of Education, Hsinchu City, Taiwan (e-mail: upshuwei@mail.nhcue.edu.tw,nancy2432730@gmail.com). demand for implementing the policies of mixed land-use.

In addition, when new urbanism advocates mixed land-use, it also emphasizes the theory and importance on Transit-Oriented Development (TOD). It means that when the policies of mixed land-use promoting, it should connect with proper transport system to achieve the purpose of well urban development. Both of land use and transportation what are the important elements of the urban or regional developed structure are inseparable [7], especially road has considered the significant substantive elements which affecting lots of urban problems [8]. Road and land use which linked with compose the urban space [9], that when exploring the issues about urban spatial activities and land use, the road network is a major and indispensable factor.

Desyllas [10] proposed the value of urban land use depends on the degree of accessibility for the overall road network, however, most of the past studies on the accessibility measuring interpreted in the shortest path and the shortest distance what neglected the impact on accessibility from road network. In order to realize the spatial characteristics of road network more, lots of "topology" theories and models have been adopted gradually in recent years. "Space Syntax" uses the location of structural elements in the system and the link relationship to produce some quantitative indicators to measure globally and local spatial structure characteristics, and the main purpose of it was provided a feasible method to measure and evaluate the of accessibility and natural activities [11]. For transportation systems, space syntax can be used to explain the convenience of the overall road network and the characteristics of spatial structural, and explore the relations between the characteristics of road network and the development of urban land use also.

In short, the characteristics of the road network structure are very important for mixed land-use, especially the impact on the spatial characteristics such as location and accessibility are closer. In order to investigate the relationship between the two spatial characteristics, this paper adopts the concept of landscape ecology, using building floor to calculate the diversity of mixed use by GIS technique and show the spatial pattern of mixed land-use in Tainan county in Taiwan, and then adopts the theory and method of space syntax to calculate the spatial characteristics about global integration value, local integration value, connectivity, and control value of the road network to explore the spatial relationship between mixed land-use and road network.

\section{Definition of Mixed LAND-Use}

To promote the tactic of mixed land-use can achieve the 
purpose of increasing intensity of use, diversity and integration quarantine, etc. [12]. For the U.S. and many European countries, mixed land-use is a creating, maintaining city attractive, livability and sustainable environment tools, for examples, two main reasons of British support for the development of mixed-use are reducing the demand for trips within the neighborhood, increasing urban diversity and vitality, and reducing crime occurred to improve security. Mixed land-use provides the quality of life in urban areas and the opportunities for attractive improvement, it also produces benefits of reducing crime, improving security and other contemporary [6]. The diversity which mixed land-use generates is considered one of the best living conditions for humans generally as well as a kind of thinking of social justice and a basis of sustainability [13].

In the definition of mixed land-use, Urban Land Institute [14] defined the plan of mixed use is an integrated plan which combines three or more functional substance as revenue and production using; Priemus et al. [15] thought that the diversity of functions in a certain space and within a certain time can be performed.

Different from functions definition, Grant [12] emphasized the use of compatible and the mixed diversity with interaction, while economists defined mixed land-use is based on the impact of interaction and aggregation between different but interactive activities [16]. In general, mixed land-use in the broadest and simplest defined as different types of land use within adjacent land in a particular area [17].

\section{DIVERSITY OF MIXED LAND-USE}

Landscape ecology is the interdisciplinary science between geography and ecology that it is the comprehensive discipline to study the type composition, spatial configuration and its interaction with the ecology. It shows the features of multi-scale and hierarchical structure in ecological system. Therefore, the theories and methods of landscape ecology has been applied to land use management, land use change, environmental and transportation planning analysis and discussion on topics gradually, such as Aaviksoo [18] used the concepts of land use transferring probability to study the types of land usage and land cover changing in three regions from 1950 to 1980, and showed the results of land-use changing through transformation matrix method in landscape ecology; Skinner [19] described the landscape structural changing of northwestern Klamath mountainous in California with GIS and metrics indicators such as area, perimeter and the distance to adjacent patches, etc in landscape ecology; Talen [13] explored the spatial diversity and distribution pattern of socioeconomic environment as income, zone of land use, residences patterns, etc.

For the urban planner, the problems of diverse land use reflect the strained relations between the single-core and multi-core, safety and excitement, convenience and separation needs to be balanced, that if combining all kinds of different usage and activities, it will be able to create a vibrant city under the principles of mutual support to operate.

Due to every indicator type of the description of landscape space has different expression meaning, on the base of the suitability of mixed land-use, this research adopting the diversity index of Shannon-Weaver to analyze the patterns of mixed land- use, the formula is as follows:

$$
H=-\sum_{k=1}^{n} P_{k} \ln \left(P_{k}\right)
$$

$H$ is the diversity index of Shannon-Weaver; $P_{k}$ is the probability in $k$ spatial unit for $k$ class; $n$ is the category total for using in the space.

\section{Measure the Spatial Characteristics of RoAd NETWORK STRUCTURE}

In order to describe and analyze the characteristics of spatial structure, Hillier and Hanson(1984) [20] developed the research methods of "Space Syntax" what basic concepts are built on the spatial structure and spatial behavior that considered from visual sensory, cognitive distance and accessibility [9], trying to explain human behavior and social activities with " axial map ". This method transforms spatial elements into dots and lines, using the structure and connective relation of point and line to interpret the spatial characteristics. After converting the physical space into the spatial topology structure illustration which is formed by dots and lines, it can discuss the relationship of relative depth between any structural element and others, so through quantitative analysis by Space Syntax on the road system is able to explain spatial characteristics as accessibility and connectivity in the road network when structural element is road network. Four basic measurable indicators as follows [20]-[22]:

\section{A. Global Integration Value, $R_{n}$}

Global Integration Value is a regional indicator for measuring the relative values of convenient from the sections of the road network to others. The larger value of $R_{n}$ expressed higher accessibility so that this section with high unobstructed will become a public gathering place easily, such as the main road, on the contrary, the lower value expressed lower accessibility where hard to arrive, most of these are the alleys which in edge of the community.

$$
\begin{gathered}
R_{n}=\frac{D_{n}}{R A_{j}} \\
R A_{j}=\frac{\left(M D_{j}-M D_{\min }\right)}{\left(M D_{\max }-M D_{\min }\right)} \\
D_{n}=\frac{2\left\{n\left[\log _{2}((n+2) / 3)-1\right]+1\right\}}{[(n-1)(n-2)]} \\
M D_{i}=\frac{\sum_{j=1}^{n} d_{i j}}{n-1}
\end{gathered}
$$

$R_{n}$ is Global Integration Value; $R A_{j}$ is Relative Asymmetry; $n$ is spatial quantity; $D_{n}$ is relative depth of all spatial quantity; $M D_{i}$ is average relative depth; $d_{i j}$ is minimum of space conversions from $i$ to $j$. 


\section{B. Local Integration Value, $R_{3}$}

$R_{3}$ and $R_{n}$ are measurable indicators to perform accessibility; the value of $R_{n}$ is measuring the "global" integration value of this section, and the value of $R_{n}$ is measuring the "local" integration value within three nodes in this section.

\section{Connectivity, $C N$}

Connectivity also called the value of connective numbers. It is the locality index to represent the number of connecting with other sections. The value larger represents the breadth of visual permeability higher, the section connects to the road directly more, public usability stronger, and accessibility higher.

\section{Control Value, C.V.}

Control value is a locality index that explores the comparison value between a section of road and its connected roads in the road network system. If all control values of weight distribution in every sections are 1 , the number of connected sections more, control value of contiguous road sections are also higher. The higher value represents the connected roads of this road section are more dependent or move out of this section.

\section{CASE Study}

Tainan county is the earliest developed urban in Taiwan, the forming of mixed land- use in Taiwan is the influencing factor in the history for urban developing, and crowds what generated by tourism for historic preservations and heritages add a lot of vitality for urban development and land use, so Tainan City is the more appropriate one than other cities in Taiwan to study. Therefore, this study explores the situation of mixed land-use change in Tainan by 2009's mixed land-use status data to analyze spatial characteristics; on the analysis unit scale selection of mixed land use pattern, the smallest units of urban spatial planning - blocks are regard as the operating unit in this study to observe the spatial developed structure of mixed land-use clearly.

The largest proportion of development Status in Tainan County is agricultural land area $(44.36 \%)$, mainly in the northern, and the downtown area are mostly residential $(10.87 \%)$ and commercial $(3.12 \%)$ usage. Various types of land use show in Fig. 1.

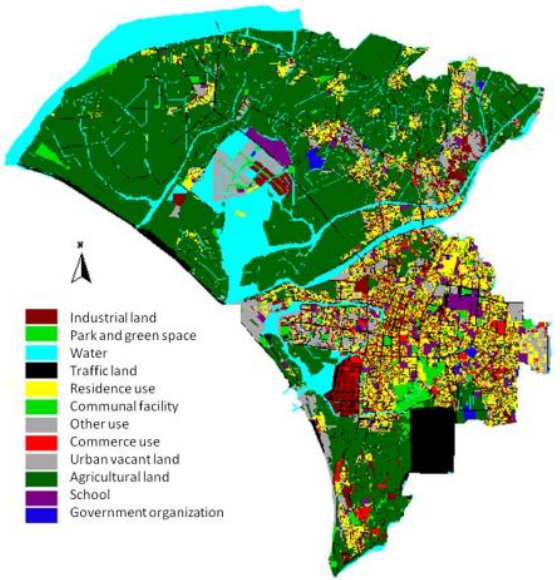

Fig. 1. The distribution of land use in 2009.

\section{A. The Diversity of the Mixed Land Use}

On the analysis unit of measuring spatial patterns of mixed land use, it selects the land use zoning for commercial, residential, industrial areas, schools, offices, public facilities, etc. blocks excluding the unit which undeveloped area larger than the half in the block that there are 4282 analysis units totally in this study. The data used in this paper is the status of land use in 2009 to calculate the mixed land use situation, the spatial distribution of blocks is shown in Fig. 2, and the statistical results are shown in Table I.

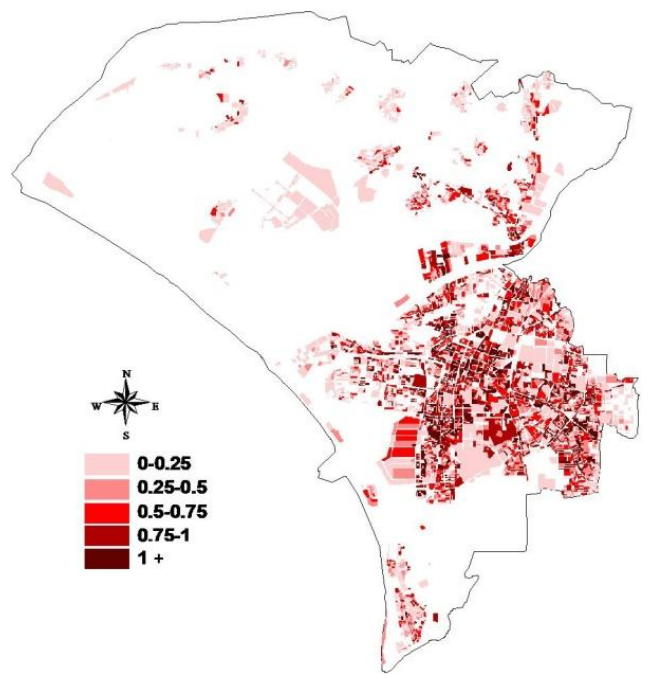

Fig. 2. The distribution of the mixed land use degree.

TABLE I: THE DATA OF DEGREE OF MIX LAND USE

\begin{tabular}{cccccc}
\hline \hline Variable & Numbers & Min & Max & Mean & Std \\
\hline Diversity & 4282 & 1.78 & 0.01 & 0.53 & 0.26 \\
\hline \hline
\end{tabular}

\section{B. The Analysis of Spatial Characteristics of Road Network Structure}

In this paper, it uses the Space Syntax method to calculate the Tainan's overall road network system for spatial structural characteristics of road network, such as global integration value, local integration value, connectivity, and control value, the results are shown in Table II. According to the spatial characteristics graph, the sections of higher global integration value are concentrated in the downtown area, the border and the lower of accessibility (Fig. 3); the sections of higher local integration value are dispersed in various communities and settlements area (Fig. 4), although the distributions are more chaos, it also can identify the communities and settlements where closer the downtown area has the higher values; most of sections of higher connectivity are important traffic junctions as the section of main road (Fig. 5); and the sections of higher control value are distributed inner the communities and settlements as the main lanes for residents passing(Fig. 6).

TABLE II: THE DATA OF SPATIAL CHARACTERISTICS OF ROAD NETWORK

\begin{tabular}{cccccc}
\hline variable & Numbers & Min & Max & Mean & Std \\
\hline Global Integration Value & 10754 & 0.66 & 0.27 & 0.44 & 0.07 \\
Local Integration Value & 10754 & 3.77 & 0.42 & 1.80 & 0.36 \\
Connectivity & 10754 & 11 & 2 & 4.41 & 1.56 \\
Control Value & 10754 & 9.55 & 0.13 & 1.06 & 0.67 \\
\hline
\end{tabular}




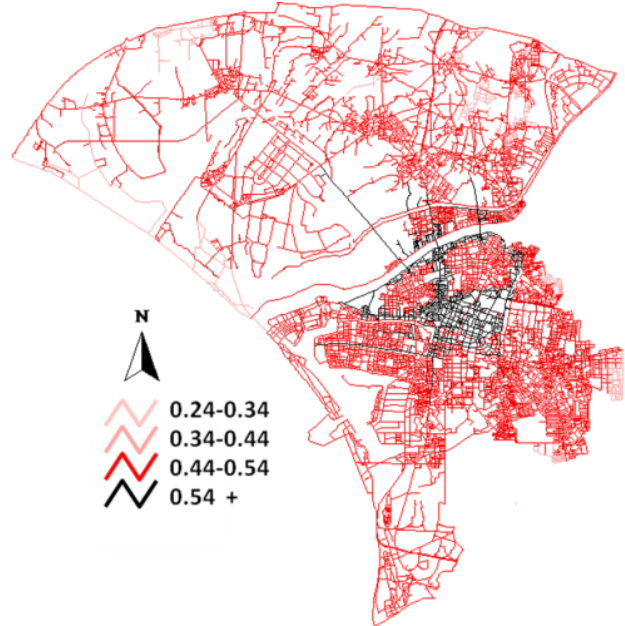

Fig. 3. The distribution of the global integration value of space syntax.

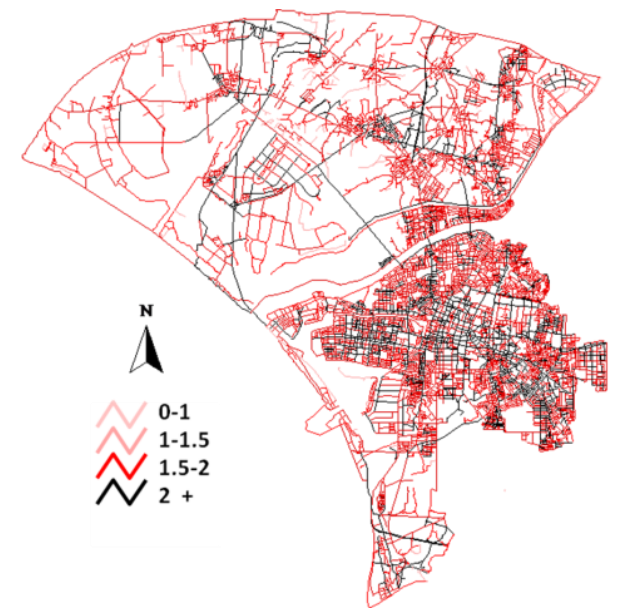

Fig. 4. The distribution of the local integration value of space syntax.

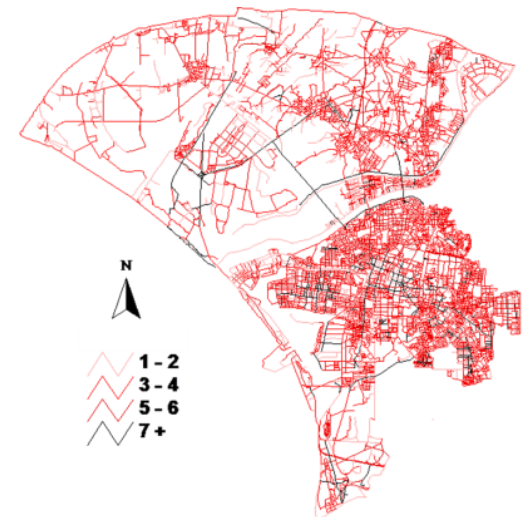

Fig. 5. The distribution of the connectivity of space syntax.

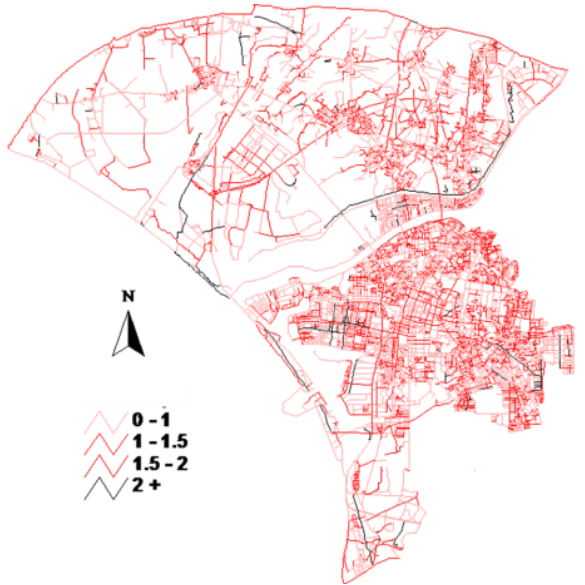

Fig. 6. The distribution of the control value of space syntax.

\section{The Correlation Analysis between Road Network and Degree of Mixed Land Use}

Correlation analysis confirmed the relevance between the degree of mixed land-use and spatial indicators of space syntax. On the basis of roads around the blocks, the study sum the value of spatial characteristics by Space Syntax calculating and link up with the blocks, then conduct the correlation analysis with the degree of mixed land-use, the analysis result are shown in the Table III. The degree of mixed land-use in Tainan is higher positive correlation with global integration value and connectivity, the correlation coefficients are 0.723 and 0.518 , as well as it is significant through the 0.01 test of significance level; however, the correlation coefficients of local integration value and control value are 0.233 and0.092, just pass the 0.05 test of significance level that relationship are less significant.

For urban developing, the place where people move easily usually has the higher accessibility of overall road network and the higher connectivity of major roads that forms the diverse land-use types and higher degree of mixed-use. The convenience of the local network affected the development of localized neighborhood, so the relevance of mixed land-use is lower. The control value affects the circumstance of roads circulation in non-downtown area that is no correlation with the degree of mixed land-use.

TABLE III: THE CORRELATION COEFFICIENTS OF MIX LAND USE AND SPATIAL CHARACTERISTICS OF ROAD NETWORK

\begin{tabular}{cccccc}
\hline Variable & $\begin{array}{c}\text { Degree of } \\
\text { mixed land use }\end{array}$ & $R_{n}$ & $R_{3}$ & $\mathrm{CN}$ & $\mathrm{CV}$ \\
\hline $\begin{array}{c}\text { Degree of } \\
\text { mixed land use }\end{array}$ & 1 & $0.723^{* * *}$ & $0.233^{* *}$ & $0.518^{* * * *}$ & $0.092^{* *}$ \\
$\mathrm{Rn}$ & 0.723 & 1 & 0.315 & 0.141 & 0.049 \\
$\mathrm{R} 3$ & 0.233 & 0.315 & 1 & 0.789 & 0.649 \\
$\mathrm{CN}$ & 0.518 & 0.141 & 0.789 & 1 & 0.943 \\
$\mathrm{CV}$ & 0.092 & 0.049 & 0.649 & 0.943 & 1 \\
\hline
\end{tabular}

** is significant at $P<0.05$; *** is significant at $P<0.01$

\section{CONCLUSION}

In summary, there are several conclusions as follows:

Combine the relevant database of land-use survey with geographic information system (GIS) can process the large and complex geospatial information rapidly and systematically, so that urban planning can be carried out more efficiently.

To reinterpret the developed patterns of mixed land use with spatial distribution characteristics by landscape ecology indicators excluding the past way that described by numerical data, it makes related research of mixed land use have considerations with spatial conditions. The analysis results are shown that the diversity value of mixed land use in downtown area in Tainan is higher, and spread out along the road.

Investigating the relationship between road network and strength of commercial development is the main purpose in this research. It adopts the view of topology what using the structures of points and line and illustrating the 
characteristics of road network by link relationships, compared to past studies, Space Syntax emphasized on the visual senses and the concepts of environmental awareness to explore characteristics such as accessibility, connectivity of road network that it fit the human actual spatial behavior and needs more. The analysis of Space Syntax shows that the relevant of accessibility within region and the diversity of mixed land use are high.

\section{REFERENCES}

[1] A. Murakami, A. M. Zain, K. Takeuchi, A. Tsunekawa, and S. Yokota, "Trends in urbanization and patterns of land use in the Asian mega cities Jakarta, Bangkok, and Metro Manila," Landscape and Urban Planning, vol. 70, pp. 251-259, 2005.

[2] S. S. Y. Lau, R. Giridharan, and S. Ganesan, "Multiple and intensive land use: Case studies in Hong Kong," Habitat International, vol. 29, pp. 527-546, 2005.

[3] Y. Song and G. J. Knaap, "Measuring the effects of mixed land uses on housing values," Regional Science and Urban Economics, vol. 34, pp. 663-680, 2004.

[4] A. Lagendijk, "Regional learning between variation and convergence: The concept of 'Mixed Land-Use' in regional spatial planning in The Netherlands," Canadian Journal of Regional Science, vol. 24, pp. 135-154, 2001.

[5] E. Burton, "Measuring urban compactness in UK towns and cities," Environment and Planning B: Planning and Design, vol. 29, pp. 219-250, 2002.

[6] E. Hoppenbrouwer and E. Louw, "Mixed-use development: Theory and practice in Amsterdam's Eastern Docklands," European Planning Studies, vol. 13, no.7, pp. 967-983, 2005.

[7] C. Woudsma, J. F. Jensen, P. Kanaroglou, and H. Maoh, "Logistics land use and the city: A spatial-temporal modeling approach," Transportation Research Part E, vol. 44, pp. 277-297, 2008.

[8] T. Chirapiwat, "Street configurations and commercial and mixed-use land-use patterns: a morphological study of the northeastern region of Bangkok to evaluate recent transportation and land-use plans," unpublished PhD thesis, Michigan: University of Michigan, 2005.

[9] H. K. Kim and D. W. Sohn, "An analysis of the relationship between land use density of office buildings and urban street configurationCase studies of two areas in Seoul by space syntax analysis," Cities, vol. 19, pp. 409-418, 2002.

[10] J. Desyllas, The Relationship between Urban Street Configuration and Office Rent Patterns in Berlin, London: University College, 1999.

[11] J. C. Foltête and A. Piombini, "Urban layout, landscape featuresand pedestrian usage," Landscape and Urban Planning, vol. 81, no.3, pp. $225-234,2007$

[12] J. Grant, "Mixed use in theory and practice: Canadian experience with implementing a planning principle," Journal of the American Planning Association, vol. 68, no. 1, pp. 71-84, 2002.
[13] E. Talen, "Land use zoning and human diversity: Exploring the connection," Journal of Urban Planning and Development, vol. 131, no. 4, pp. 214-232, 2005.

[14] Urban Land Institute, Mixed-Use Development Handbook, Washington D.C.: Urban Land Institute, 1987, pp.1-46.

[15] H. Priemus, P. Nijkamp, and F. Dieleman, Meervoudig Ruimtegebruik; Stimulansen en Belemmeringen, Delft: Delft University Press, 2000.

[16] P. Nijkamp, C. A. Rodenburg, and R. Vreeker, The Economics of Multifunctional Land Use, Maastricht: Shaker Publishers, 2003.

[17] S. L. Handy, M. G. Boarnet, R. Ewing, and R. E. Killingsworth, "How the built environment affects physical activity-Views from urban planning," American Journal of Preventive Medicine, vol. 23, pp. 64-73, 2002.

[18] K. Aaviksoo, "Changes of plant cover and land use types (1950's to 1980 's) in three mire reserves and their neighborhood in Estonia," Landspace Ecology, vol. 8, no. 5, pp. 287-301, 1993.

[19] C. N. Skinner, "Change in spatial characteristics of forest openings in the Klamath Mountain of northwestern California, USA," Landscape Ecology, vol. 10, no. 4, pp. 219-228, 1995.

[20] B. Hillier and J. Hanson, The Social Logic of Space, Cambridge: Cambridge University Press, 1984.

[21] B. Jiang and C. Claramunt, "Integration of Space Syntax into GIS: new perspectives for urban morphology," Transactions in GIS, vol. 6, no. 3, pp. 295-309, 2002

[22] A. S. Choi, S. J. Jang, B. C. Park, Y. O. Kim, and Y. S. Kim, "Rational-design process and evaluation of street-lighting design for apartment complexes," Building and Environment, vol. 42, pp 3001-3013, 2007.

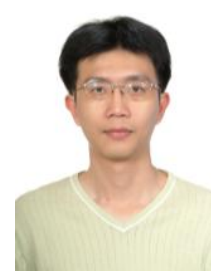

Shu-Wei Huang received the Ph.D. degree in 2008 in Department of Urban Planning of National Cheng Kung University, Taiwan. Currently, he is an assistant professor in Department of Environmental and Cultural Resources of National Hsinchu University of Education in Taiwan.

He occupies a commissioner in the Committee of Urban Design and Land Use Development Permit and Committee of Program advancement of Urban Renewal in Hsin-Chu City Government in Taiwan. His research interests include urban planning, spatial analysis and land use change.

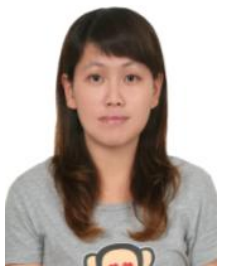

Hsiu-I Hsieh was born at Tainan City, Taiwan on July 30, 1990. She received her B.S. degree in Departmen of Environmental and Cultural Resources, National Hsinchu University of Education, Hsinchu City, Taiwan, from 2008 to 2012. She is now a M.S. student at Department of Environmental and Cultural Resources, National Hsinchu University of Education, Hsinchu City, Taiwan. 